\title{
Environment Hygiene in the Nigerian Urban Cities (A Case Study of Enugu Urban)
}

\author{
Rosemary Ndidiamaka Ene
}

\begin{abstract}
This paper examined the environmental hygiene in the Nigeria urban cities. The paper observed the poor hygiene and the problems of Nigeria urban cities and identified the problems that have aided the poor hygiene of the urban cities as; i) poor town planning implementation, ii) improper waste management and disposal, iii) poor sanitation, iv) overcrowding and $v)$ poor ventilation. These conditions have serious adverse impacts on the health of the urban dwellers. The paper also suggested strategies for improving the environmental hygiene of the Nigerian urban cities, for healthy living and sustainable urban growth and development. The paper again used graphical representations to show water availability and sources to ascertain the poor sanitation and hygiene of the urban cities.
\end{abstract}

Index Terms-Environmental hygiene, overcrowding, sanitation, ventilation.

\section{INTRODUCTION}

The environment in many developing countries particularly Nigeria, is unhygienic. The factors responsible for this can be attributed to rapid urbanization, rural - urban migration, decades of steady economic downturn, decay of urban infrastructure and negligence of urban housekeeping [1].

Urbanization process in many developing counties particularly Nigeria, has not been accompanied with a corresponding supply of adequate amenities, such as modern houses, drainages and other infrastructures [2]. These have created demands on housing stocks leading to high rents, overcrowding and development of slums and squatter settlements which have serious impacts on the sanitation of the urban environment and enormous consequences on the health of the city residents. The relationship between the physical environment and human health has been on the World Health Organization's (WHO) focus since its inception. In its original constitution of 1946, the WHO's core functions included the promotion of improved housing, sanitation, recreation, economic and working conditions and other aspects of environmental hygiene.

Over the decades, the environment and health nexus have remained much the same but many man-made factors haverisen in prominence and impact. Such factors include air, water and soil pollution and the influence of industrially produced chemicals in consumer products [1]. The physical

Manuscript received June 15, 2013; revised August 17, 2013.

Rosemary Ndidiamaka Ene is with Department of Basic Science, Institute of Management and Technology, Enugu, Nigeria (e-mail: ojidiemenwaene@yahoo.com). environment which refers to the buildings and spaces between them, is considered the most important component of the environment because it is that with which the organisms, individuals, community or population is in direct contact and whose effect are mostly directly visible and tangible. The major elements of the physical environment as identified by [3] include home, its structural stability, amenity, architecture, and location characteristics, relative to the home.

This paper will examine the reasons for poor hygiene of the Nigerian urban environment and its effect on health of the city dwellers. It will also proffer solutions that could improve the city environment for sustainable human settlement and development. The paper paid particular attention to the situation in Enugu urban.

\section{STUDY METHODS}

This study has mainly relied on the qualitative method of research. Most of its data has been collected through library research. Some primary data used in the work has been collected through personal observation and photographs taken by the researcher.

\section{THE Problems OF ENVIRONMENT HyGIENE IN THE Nigeria URban Cities}

To effectively improve the hygiene and sanitation conditions of the urban environments, we must first analyze the problems; understand the characteristics and then tackle them. The problems include:

- Poor town planning implementation

- Improper waste management and disposal

- Poor sanitation

- Overcrowding

- Poor ventilation

\section{A. Poor Town Planning Implementation}

Some of Nigerian urban centers for instance Enugu metropolis, even though it has been a capital city for decades, still lack essential basic amenities such as pipe borne water, electricity, and good road network. Where the facilities are available, they are insufficient or do not most often function properly due to neglect by the relevant authorities and therefore could not meet with the needs of the users. Some parts of Enugu, one of the oldest metropolitan cities in Nigeria like most of the urban centers are not properly planned and are products of grown development. In some cases the roads are narrow and are congested by traffic and tricycles especially in those areas that have been transformed to business areas. However the 
present administration, by Governor Sulivan Chime has embarked on massive urban infrastructural development and waste management strategies but due to population explosion only little is noticed in the efforts of the Sullivanled administration in Enugu state.

\section{B. Improper Waste Management and Disposal}

Waste disposal is a major problem in our urban centers especially in most slum areas and squatter settlements. There is not enough planned disposal sites for refuse with a resultant indiscriminate disposal of refuse on any available space (Fig. 1(a) and Fig. 1(b)). Some houses are not provided with toilet facilities and people defecate indiscriminately. Many of the city dwellers practice "bush method" (see Fig. 2). The consequence is that some areas are filthy and dirty and emit offensive odor. This makes the inhabitants vulnerable to diseases attack.

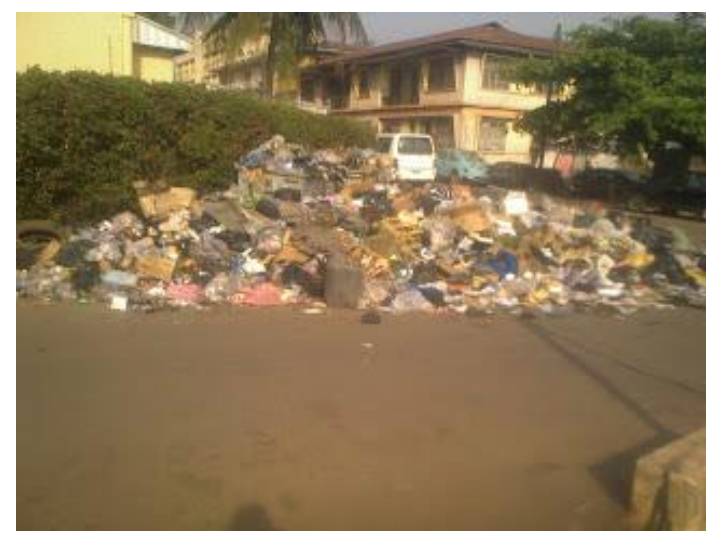

Fig. 1(a)

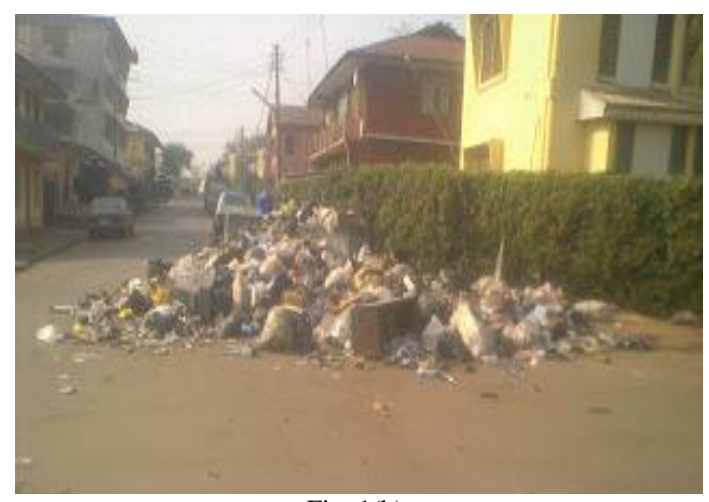

Fig. 1(b)

Fig. 1. Refuse dumps by residential quarters in Enugu.

Drainage facilities are absent in some areas. This gives rise to flooding in such areas during heavy rain falls. In most cases, the inhabitants worsen the problem by throwing their wastes into moving flood which end up blocking the drainage systems. Some are rendered homeless during heavy rain falls, some residents cannot access their homes with vehicles.

\section{Overcrowding}

Another noticeable characteristic of Nigerian urban centers is overcrowding arising from overpopulation and insufficient accommodation. The occupancy rate in some of our urban centers is as high as six per room. There are instances where as many as 10 persons are crammed up in a tiny makeshift room less than 10 square meters, not by choice but by overbearing circumstances.

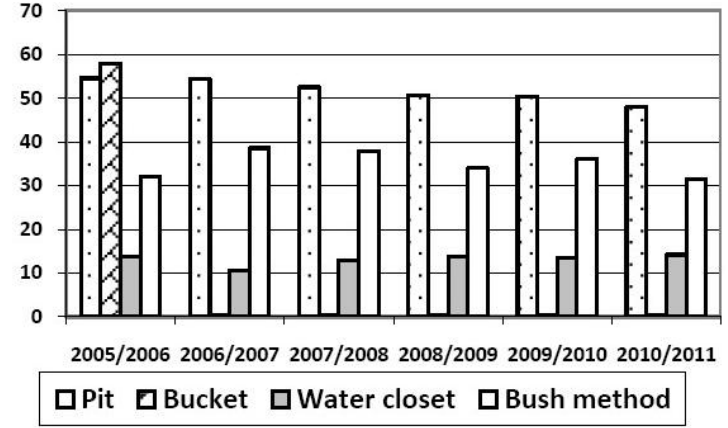

Fig. 2. Distribution of households by types of toilet facility. Source: Enugu state office of statistics (2008).

Overcrowding is a problem that has social and health effects. Reference [4] observed that overcrowding is a specific happening, clinically observable and definable.

In simple terms, overcrowding occurs when organisms are brought in such a manner and number as to produce physical reactions of stress. Important among these reactions is the increase in the activity of the adrenal secretion thus leading to increased action of the sympathetic nervous system. When these reactions to stress are widespread and sustained, they are followed by physical wakening sometimes rage and violence or extreme passivity, a rise in sexual aberrations and a breakdown of orderly group behavior. What may follow is a tidal wave of deaths, which can only end when the population is no longer crowded [5].

Reference [5], in his own study linking human dwelling space with stress, considered the number of square meters per person in the home. The study found that when each person had less than 8 to 10 square meters, the instances of physical illness and behavior were double than those in less crowded homes. This human crowding was clearly linked with illness and violence.

Overcrowding is especially obtainable in slums and squatter environment. It can destroy the quality of human life through many mechanisms such as water shortage, environmental pollution, spread of disease, survival of the fittest, etc. Many of our city dwellers still lack portable water supply, the instance of water shortage is depicted below (Fig. 3).

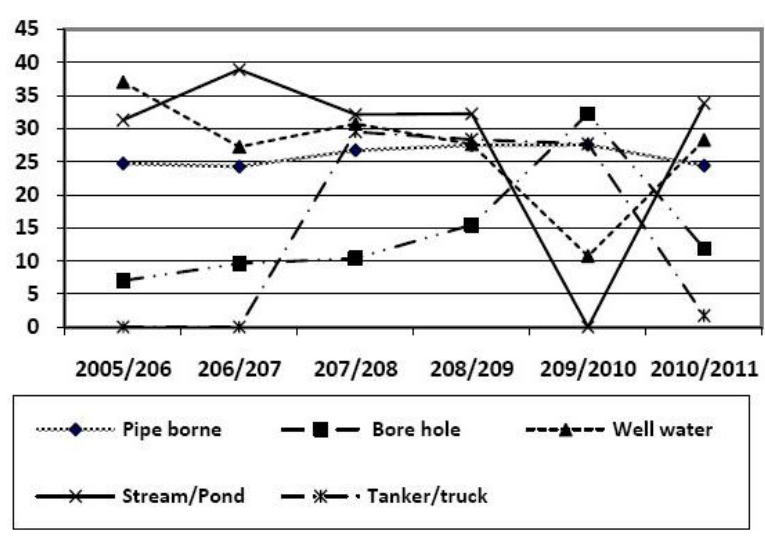

Fig. 3. Distribution of households by types of water supply (\%). Source: Enugu State office of statistics (2008).

\section{Poor Sanitation}

Globally, over one billion people lack access to safe 
water and 2.6 billion lack accesses to safe sanitation. One of the well-known environmental health consequences of this situation is that there are about 4 billion cases of diarrhea every year, which cause about 1.8 billion deaths, mostly among children under five years of age [6].

Close to one fifth of the burden of diseases in developing countries can be attributed to sanitation related environmental risk. Much of these fall on our children especially those under five years of age as about two-fifth of infant mortality is associated with environmental factors. When we look at the major environmental risks, about 1.7 million premature deaths are attributable to unsafe water, poor sanitation and poor hygiene. As many as one-third of these occur in Africa. Urban air pollution is estimated to result in about 800,000 premature deaths annually, and many developing countries are rapidly urbanizing.

Sanitation is very much a forgotten problem globally. Much of the spending by the United Nations in year 2000 was estimated at only 1 billion dollars, less than $10 \%$ of 13 billion spent on water, even though twice as many people lack basic sanitation [6]. In many countries of Africa, the scale of the problem is increasing. Adequate and effective sanitation in Nigeria and many other developing countries seems a myth for good health and sustainable human development.

According to a World Bank study as reported by [7], 360400 million people are living in malaria prone areas. More than 200 million episodes of clinical diseases resulted in 1 million deaths from malaria in 2000. These frightening figures call for concerted efforts on the part of various levels of government in Africa, particularly Nigeria, to be more committed to sanitation matters.

The World Bank has since engaged in a booster program for malaria control in Africa. One of such initiative is the Roll Back Malaria program (RMB). The World Bank Global Strategy and Booster program posited in 2005 that if at least $60 \%$ of children less than five years slept under Insecticide Treated bed Nets (ITNs) there could be as much as 20 percent reduction in mortality and morbidity. Nigeria is still far from reaching this level of coverage due partly to production and distribution related bottlenecks, as well as significant financing gaps.

Poor sanitation encourages breeding ground for dangerous disease carrying insects. The possibility of epidemic, such as diarrhea and Lassa fever cannot be ruled out in most of these unhygienic environments. Health is wealth, therefore it behooves on the various levels of governments in Nigeria and other African countries to embark on well-coordinated sanitation measures. This would help reduce the disease infested illnesses and ensure sustainable growth in Nigeria.

\section{E. Poor Ventilation}

Reference [8] noted with regret that most people in the developing countries of Asia, Latin America and Africa, live in dwellings which could be considered dangerous to health and unsuitable to human dignity. This is mostly reflected in houses that lack proper ventilation and lighting. In some Nigerian homes, adequate ventilation is not considered while planning for residential buildings despite that this is the most vital aspect of construction that makes for comfortable living.

Reference [9] noted that most residential buildings have been planned, designed and constructed with little or no consideration for thermal comfort of the occupants through the process of cross ventilation, prevention of the entry of rain and moisture into the building, and outdoor living possibility within the compound, yet the importance of ventilation in homes and other large space cannot be overemphasized.

As a result of poor ventilation in most buildings, people sleep outside, with their mats, for fresh air especially during the dry season when the weather is hot. This is as a result of their houses either not being cross ventilated or blocked by another house or fence due to improper planning of the environment. Sometimes the windows are attached as an afterthought. The life span of any one exposed to excessive heat for too long is shortened. It also has adverse effect on the skin, internal organs and physical well-being. This results in infertility. Others include asthma, tuberculosis, dizziness, stress and restlessness, and a host of others.

\section{STRATEGIES FOR IMPROVING ENVIRONMENT HYGIENE IN NIGERIAN URBAN CITIES}

From the foregoing, it has been established that most Nigerian urban cities are in unsanitary and unhygienic conditions. The citizens cannot do much; therefore government at various levels must step in and "help" the citizens. In the spirit of Millennium Development Goals (MDGs) and sustainable development, international bodies must also step in.

These tools should be used effectively to ensure a healthier urban development for sustainable development. To achieve these objectives we must do the following:

1) Ensure the creation of aesthetic values and beautification in our urban cities. Architecture of the environment can satisfy some of the psychological needs of the people in a community. Visual pleasures relax a troublesome heart and aids longevity. Good landscaping is a powerful tool to achieve a pleasant environment. Landscaping contributes to a visual satisfaction, which could have a profound effect on the psychological nature of man.

2) Therefore, urban development should attempt to provide for aesthetics and beautification especially through the creation of open spaces of a designed quality to accompany such development

3) Creating beautiful environment and community through a deliberate search for beauty, backed by a lively appreciation of the visual world by people. Therefore aesthetics and visual arts are taught in our schools beginning from the primary.

4) Ensure that we stimulate effective urban and rural development program by the provision of basic amenities, services and infrastructural facilities as well as small scale industries.

5) These would encourage development in rural areas and consequently serve as growth poles and spring boards for the redistributing of population and traffic patterns for sustainable development.

6) Ensure that the international agencies continue to 
support us through their programs aimed at improving our environment and health projects to ensure better environment.

7) Ensure public campaigns on educating and enlightening people on sanitation and environmental matters.

8) Ensure provision of facilities required for achieving good disposal systems. The mass distribution of refuse bins by the Enugu State Government is a welcome development. The Waste to Wealth (recycling) program by the Lagos state government is very commendable.

\section{CONCLUSION}

The above measures are imperative for us to have a harmonious, attractive and aesthetic pleasing environment devoid of health hazards. It is believed that if these recommendations are implemented, our urban cities will grow in an environmentally harmonious way. Furthermore; unplanned growth will be checked and prevented. These measures will save untimely death and improve the life expectancy of the average Nigerian.

\section{REFERENCES}

[1] World Bank, "Global strategy and booster programme," Annual Review, pp. 32, 2005

[2] S. O. Osuide and K. O. Dimuna, "None compliance with building bye-laws and regulations in Nigeria - the dangers ahead," The Built
Environment Journal of International Institute for Building Research (IIBR), vol. 1, no. 1, pp. 62-68, 2005.

[3] A. Essagha, Urban Planning Concepts Standards and Symbols, Lagos: Amfitop Book Nig. Ltd., 1997, pp. 17-19.

[4] B. Asbell, "The danger signals of crowding," Think Magazine, New York, July-August 1975, pp. 30-33.

[5] P. Chombant, M. Chombant, and B. Asbell, "The danger signals of crowding," Think Magazine, New York, July-August 1975, pp. 30-33.

[6] T. Simon, "Sanitation: no silver bullets but reasons for hope," Environment Matters Annual Review, World Bank, Washington D.C., 2005, pp. 12.

[7] F. M. Doumani, Environmental Health in Sub-Saharan Africa: Effective Interruptions, (Draft), World Bank, Washington D.C., 2005.

[8] UNDP, The United Nations Development Decades (1960-1970) Report, Technical Report Series 275, pp. 1-11, 1975.

[9] S. O. Izomoh and J. I. Olomu, "The effects of poor architectural design and poor application of appropriate technology on the health of the occupants of residential buildings (Nigerian situation)," The Built Environment Journal of International Institute for Building Research (IIBR), vol. 1, no. 1, pp. 3, 2005.

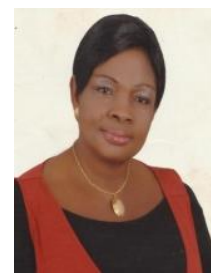

Rosemary Ndidiamaka Ene was born on July 15 , 1965 at Enugu, Nigeria. She obtained her bachelor of science degree in applied biochemistry at the Anambra State University of Technology, Enugu, Nigeria. She also holds a master of science degree in environmental resource management obtained at the Imo State University, Owerri, Nigeria. She is currently running a Ph.D. program at the University of Nigeria, Enugu Campus. She is presently a principal lecturer and head of Department of Basic Science, Institute of Management and Technology, Enugu, Nigeria. 